\title{
First record of the genus Sinamphiascus (Copepoda: Harpacticoida) from Korean waters
}

\author{
Eunjung Nam ${ }^{1}$ and Wonchoel Lee ${ }^{2, *}$ \\ ${ }^{1}$ National Institute of Biological Resources, Incheon 404-170, Korea \\ ${ }^{2}$ Department of Life Science, College of Natural Sciences, Hanyang University, Seoul 133-791, Korea \\ *Correspondent:wlee@hanyang.ac.kr
}

\begin{abstract}
A harpacticoid copepod, Sinamphiascus dominatus Mu \& Gee, 2000 is re-described from the sandy bottom in off Jeju Island of Korea. The genus Sinamphiascus was established with single species, S. dominatus from the Bohai Sea, China. The main diagnostic characters of the specimen from Korea are well matched with the original description, although it has minor discrepancies including the lengths and ornamentation of setae in leg 6 of both sexes, shape of the base on furcal setae and teeth number of labrum in female. However those discrepancies are regarded to the intra-specific variations. This is the first record of genus Sinamphiascus in Korean waters.
\end{abstract}

Keywords: Copepoda, Harpacticoida, Jeju Island, Korea, Miraciidae, Sinamphiascus dominatus

\section{INTRODUCTION}

The family Miraciidae Dana, 1846 is huge family of benthic copepods (Boxshall and Halsey, 2004). The family Miraciidae includes 51 genera, 457 species (Wells, 2007), while only eight genera 13 species have been recorded in Korea (Song and Chang, 1995; Yoo and Lee, 1995; Song et al., 1999; Lee et al., 2007; Song et al., 2007; Chang, 2009; Kim et al., 2011; Park and Lee, 2011).

The genus Sinamphiascus was established to accommodate $S$. dominatus from the Bohai Sea, China (Mu and Gee, 2000). This species was the most common sublittoral miraciid in the Bohai Sea. Their seta ornamentation of the swimming legs identifies it as a Bulbamphiascus but it has a closer relationship with Haloschizopera by several characters, the form of the P1 endopod, the antennule, the antenna, the female genital field, the spinulation of the urosome and caudal ramus, and sexually dimorphic characters on the male P1 basis and P2 endopod (Mu and Gee, 2000).

During a study of the harpacticoid copepods from off Jeju Island in the South Sea of Korea, Sinamphiascus dominatus was discovered. In this study, we provide a redescription of $S$. dominatus based on the newly collected specimens from Korea.

\section{Materials ANd Methods}

The specimens of Sinamphiascus dominatus collected from five stations off Jeju Island, South Sea of Korea in 2002, and from the Southwest sea of Korea in 2009. Sediments were collected by a box corer at each station and five replicates were taken from each box corer. Sediments were subsampled using a $2.7 \mathrm{~cm}$ (internal) diameter syringe from the box corer. Meiofauna was extracted from sediments by Ludox-AM method (Burgess, 2001). Harpacticoids were sorted out and counted under a dissecting microscope, and stored in $70 \%$ ethanol.

Dissection and size measurement of copepods were carried out with specimens soaked in lactic acid under the stereomicroscope (Olympus SZX 12). Specimens were mounted on slides using lactophenol as mounting medium. All illustrations were drawn with the aid of a drawing tube attached to a microscope (Olympus BX51). Preparations were sealed with transparent nail varnish. The specimens were deposited in the NIBR (National Institute of Biological Resources, Korea).

The descriptive terminology follows Huys et al. (1996). Abbreviations used in the text are as follows: A1, antennule; A2, antenna; ae, aesthetasc; exp, exopod; enp, endopod; P1-P6, first to sixth thoracic legs (thoracopods); $\exp (\mathrm{enp})-1(2,3)$ to denote the proximal (middle, distal) segment of a ramus.

\section{Systematic Accounts}

Order Harpacticoida Sars, 1903

Family Miraciidae Dana, 1846

Genus Sinamphiascus Mu and Gee, 2000 


\section{Sinamphiascus dominatus Mu and Gee, 2000 (Figs. 1-8) \\ Sinamphiascus dominatus $\mathrm{Mu}$ and Gee, 2000, P. 119- 127, Figs. 15-21.}

Material examined. a) 2 우 우 (KOSP IV0000145448), and 1 우 (KOSP IV0000145452) in 70\% ethanol from Southern West Sea of Korea on 20 May and 25 August 2009, collected by Hong JH; b) 4 우 우 and $3 \sigma^{7} \sigma^{7}$ dissected and placed on 10, 9, 6, 8, 7, 6 and 5 slides from off Jeju Island, Korea during the periods from September 24 to 272002 collected by Song YH \& Nam E.

Female: Body (Fig. 1A, B) subcylindrical, 370-540 $\mu \mathrm{m}$ long. Rostrum (Fig. 1A, C) defined at base, elongate, triangular, semi-hyaline distally, and extending beyond second antennular segment, with pair of small sensilla on lateral margins. Urosome (Figs. 1A, B) 5-segmented, comprised of P5-bearing somite, genital double-somaite, and 3 free abdominal somites. First three urosomite with denticulate hyaline frills on posterior margin. Genital double -somite (Figs. 1A, 3B) marked by continuous internal chitinous rib dorsally and laterally, and discontinuous rib ventrally. Genital field (Fig. 3B) with separate genital apertures, each covered by P6 bearing 2 plumose setae and 1 short spine. Anal somite (Fig. 3C) with small semicircular operculum near middle of anterior dorsal border, and overlain by 1 small pseudoperculum.

Caudal rami (Fig. 3B, C) quadrate with 1 slender tube pore on ventral posterior margin between seta IV and V and few spinules on inner margin; seta I well developed and located on small peduncle, seta II well-developed on lateral margin, seta III small and smooth, located on small peduncle, terminal seta IV and V well-developed and spinulose in median and terminal portion, seta VI welldeveloped and slightly plumose, seta VII triarticulate.

Somatic ornamentation (Fig. 1A, B). All somites furnished with numerous sensilla and pores distributed as Fig. 1A. All urosomite except urosomite-1 with some spinule rows on dorsal or lateral side.

Antennule (Fig. 3A) 8-segmented, segment 2 largest. Aesthetasc on segments 4 and 8; Armature formula as follows: 1-[1 plumose], 2 -[7 bare +5 plumose], 3 -[ 3 bare +2 plumose], 4-[3 bare $+(1+\mathrm{ae})$ ], 5-[2 bare], 6-[4 bare], 7-[3 bare +1 plumose], 8 -[5 bare+acrothek], apical acrothek consisting of aesthetasc fused basally to 2 slender naked setae.

Antenna (Fig. 3D) 3-segmented comprising coxa, allobasis and free 1-segmented endopod. Allobasis with 1 plumose abexopodal seta medially. Exopod 3-segmented with seta formula 1.1.120. Exopodal segments 1 and 2 with 1 bipinnate seta respectively and segment 3 with 1 bare seta on lateral margin and 2 unipinnate setae on terminal margin. Free endopodal segment with 1 row of strong spinules on outer margin, rows of smaller spinules on dorsal and ventral sides, and with 1 bare spine and 2 unipinnate spines on lateral margin and 4 geniculate setae, 2 bare setae and 1 bipinnate seta on distal margin.

Labrum (Fig. 2E) posterior margin armed with 2 groups of 4 teeth and 2 median submarginal rows of spinules.

Mandible(Fig. 2A) with coxa bearing well-developoed gnathobase armed with 1 large bicuspid tooth, 1 tricuspid, 2 bicuspid, 1 multicuspid, and 2 unicuspid teeth, with 2 setae at inner distal corner. Mandibular palp developed. Basis with 2 plumose setae and 1 bipinnate seta on distal margin. Endopod large and 1-segmented; with 1 bare and 1 plumose seta on proximal region and 1 bare and 1 unipinnate seta on subdistal region and 3 setae fused at base on distal margin (1 unnipinate). Exopod 2-segmented; segment 1 with 1 plumose seta, segment 2 with 2 bare setae and 1 plumose seta.

Maxillule (Fig. 2B). Arthrite of praecoxa well-developed, with 2 smooth setae on anterior face; distal margin with 9 spines and 1 bare seta on inner margin. Coxa with 2 naked setae on distal margin. Basis longer than wide with 1 plumose seta and 5 bare setae on distal margin. Enopod 1-segmented with 1 bare and 3 plumose setae on distal margin. Exopod 1-segmented with 2 plumose setae.

Maxilla (Fig. 2C). Syncoxa with 3 endites; proximal and middle endite armed with 2 spines ( 1 smoothe and 1 pectinate), distal endite with 3 pectinate spines. Allobasis produces into strong claw with 1 spine and 2 slender setae, Endopod 1-segmented, with 6 setae in total.

Maxilliped (Fig. 2D) comprising syncoxa, basis, and endopod. Syncoxa with 2 surface rows of spinules; distal margin with 3 pinnate setae. Basis with 2 setae on median and distal parts. Endopod with 1 terminal claw and 3 accessory setae.

Swimming legs 1-4 biramous with 3-segmented exopod and 3-segmented endopod, and each ramus ornamented with setules and spinules along inner and outer margins as illustrated.

P1 (Fig. 4A), intercoxal sclerite quadrate without ornamentation. Coxa with 2 rows of spinules on anterior surface, 2 rows of long spinules on outer margin, and spinular and setular rows on inner margin. Basis with row of setules on inner margin and row of spinules on median anterior face and distal margin; outer basal spine bipinnate. Exopod with row of strong spinules on outer margin, shorter than endopod, and reaching end of enp-2; exp-2 with row of setules and 1 plumose seta on inner margin; exp-3 with 2 geniculate setae on distal margin and 2 spines on outer margin. Endopod non-prehensile, all segments subequal in length; each with row of spinules on outer margin and enp-1 with row of setules on inner margin; enp-1 and enp-2 with 1 plumose seta on inner margin; enp-3 with 1 plumose seta, 1 large, geniculate, unipinnate seta and 1 spine on distal margin.

P2-P4 (Figs. 4B, 5A, B), intercoxal sclerite strongly de- 


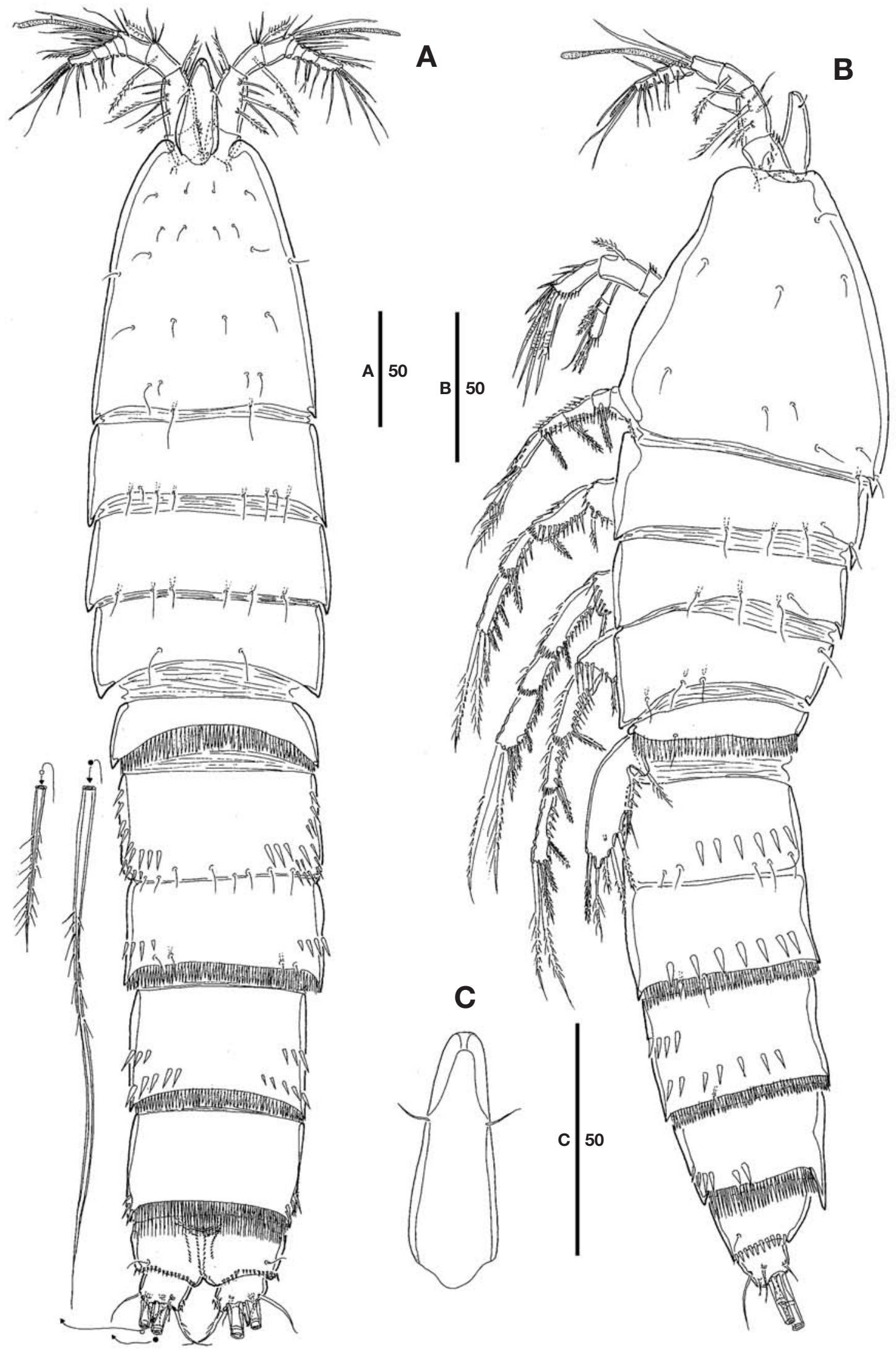

Fig. 1. Sinamphiascus dominatus, female. A. habitus, dorsal. B. habitus, lateral, ventral. C. rostrum. 


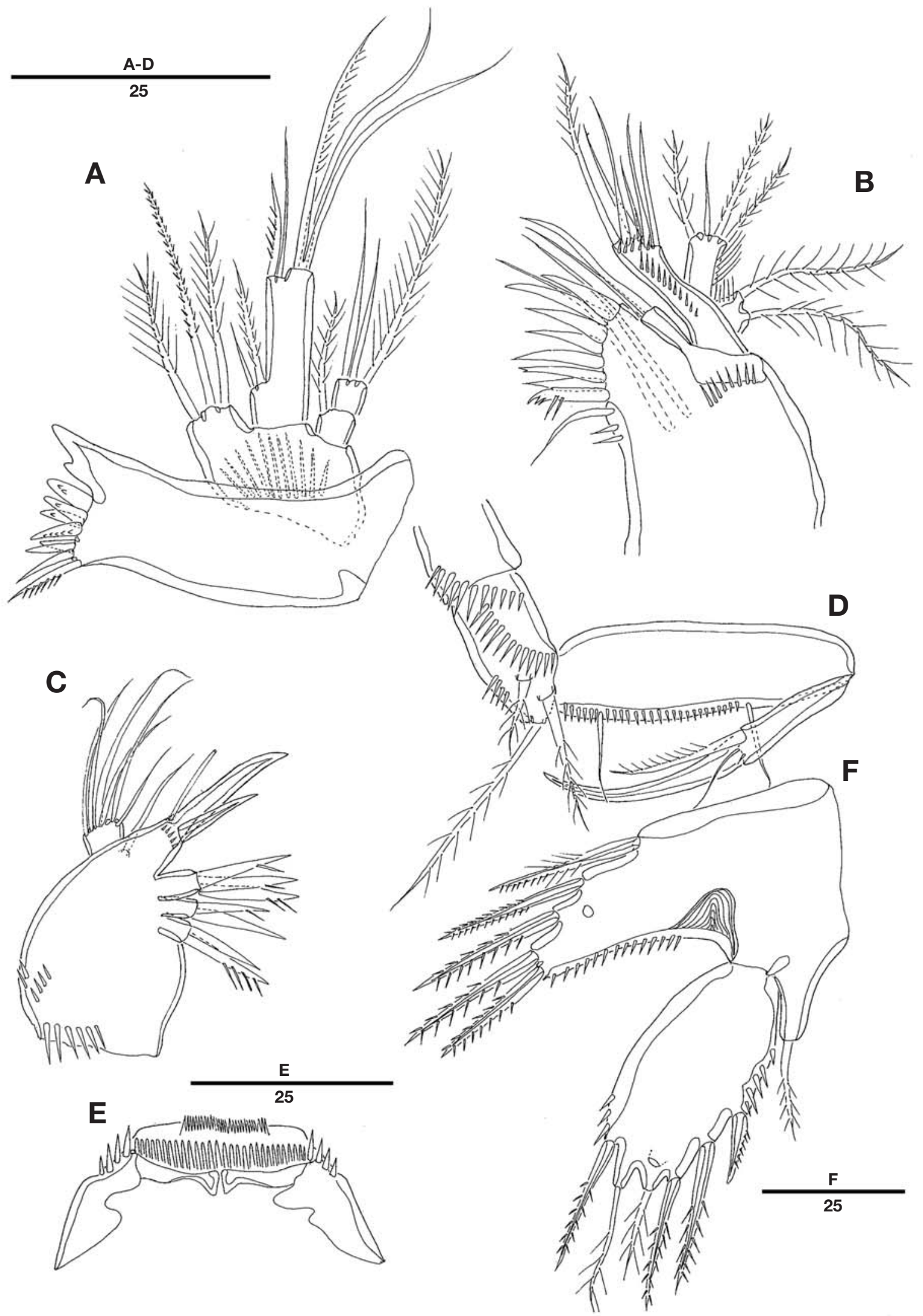

Fig. 2. Sinamphiascus dominatus, female. A. mandible. B. maxillule. C. maxilla. D. maxilliped. E. labrum. F. P5. 


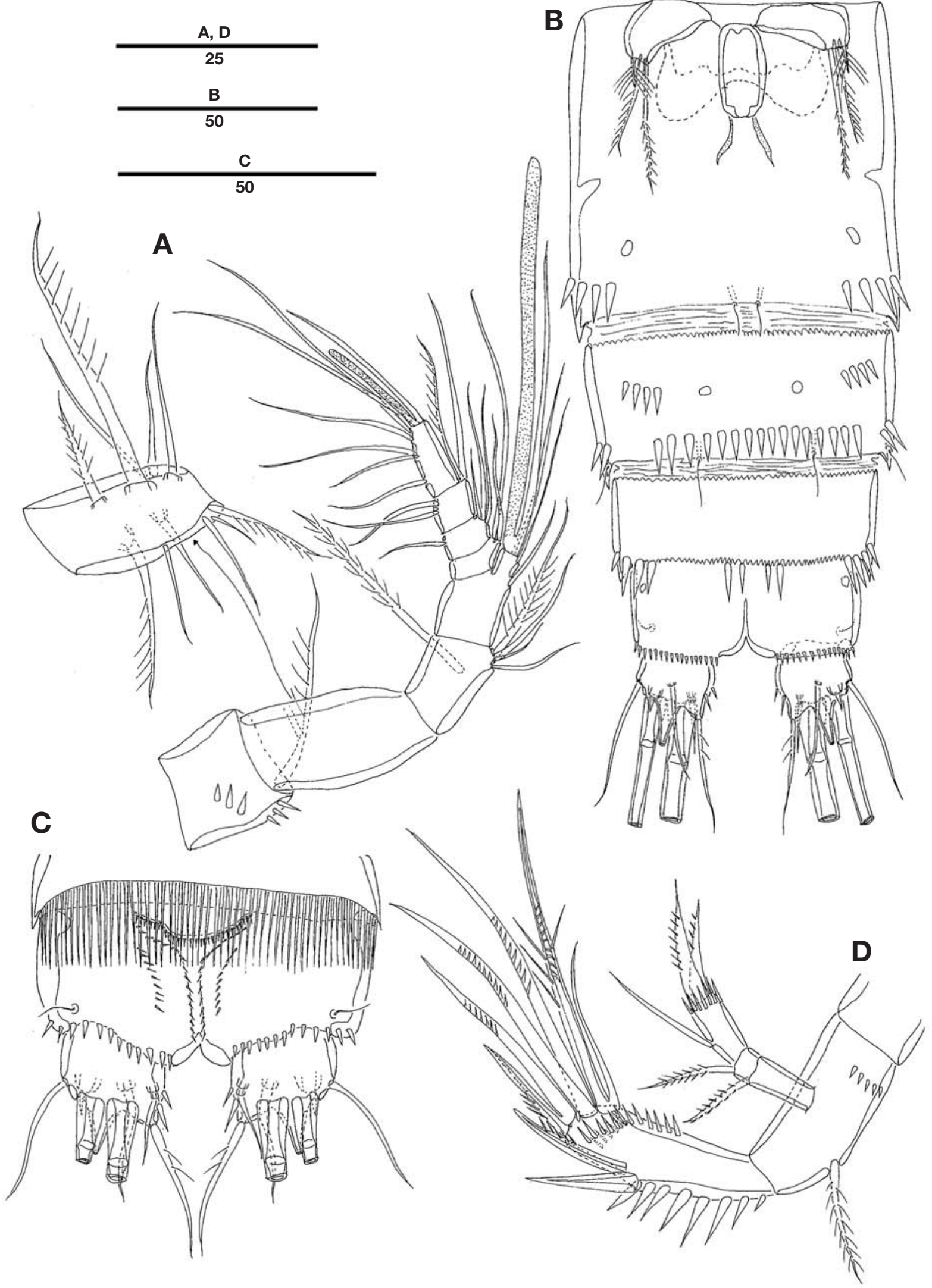

Fig. 3. Sinamphiascus dominatus, female. A. antennule. B. urosome, ventral. C. anal somite, dorsal. D. antenna. 


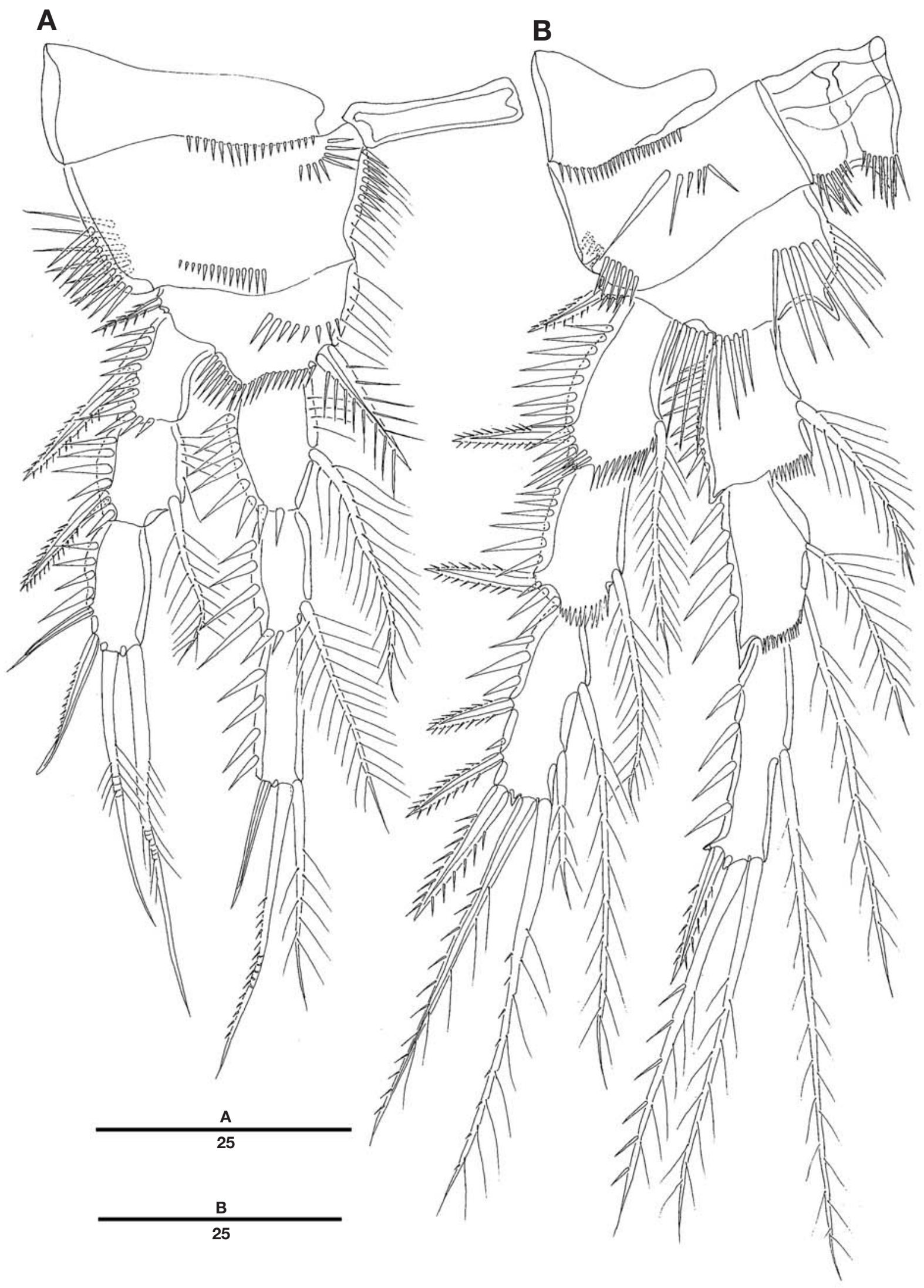

Fig. 4. Sinamphiascus dominatus, female. A. P1. B. P2. 


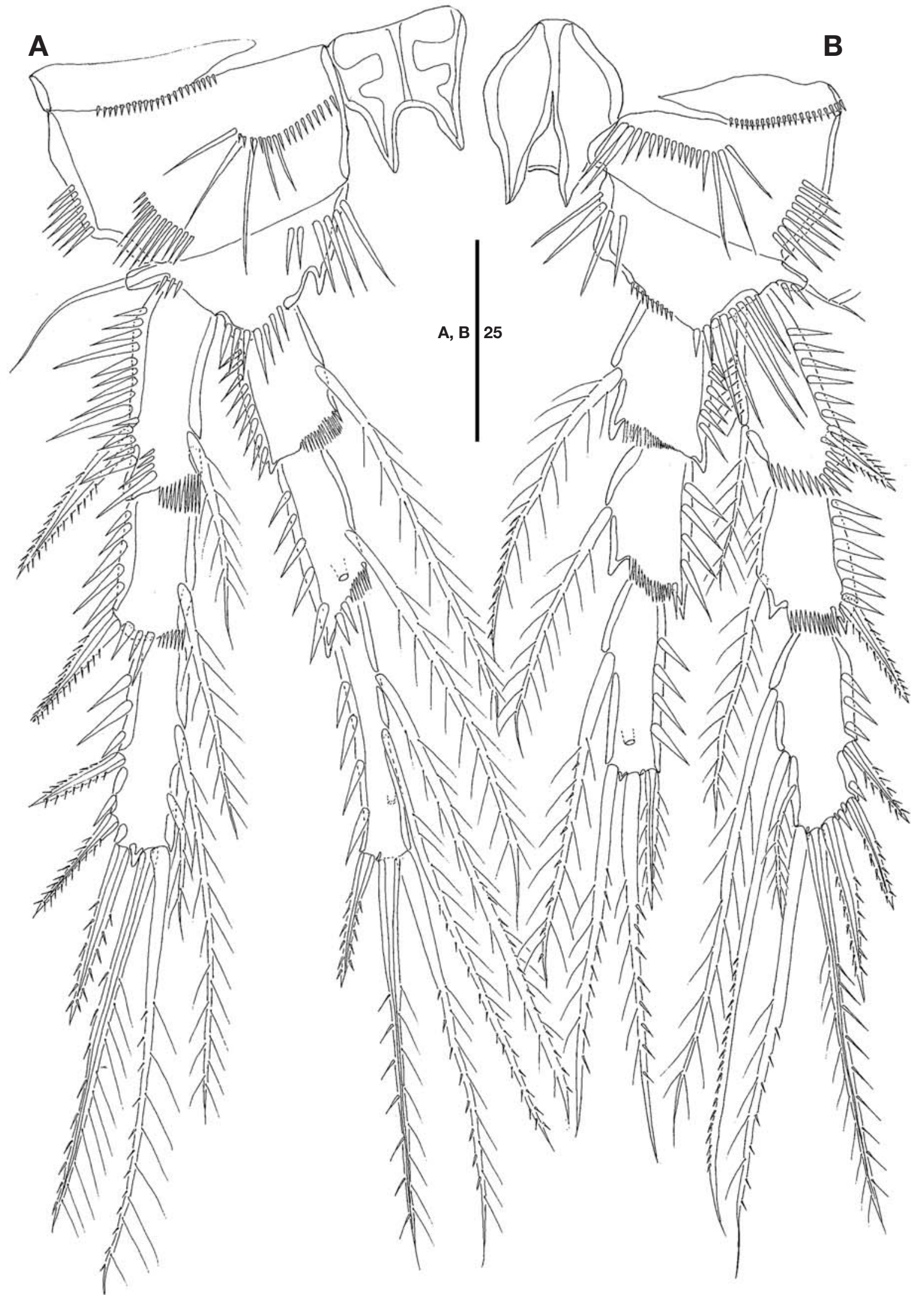

Fig. 5. Sinamphiascus dominatus, female. A. P3. B. P4. 


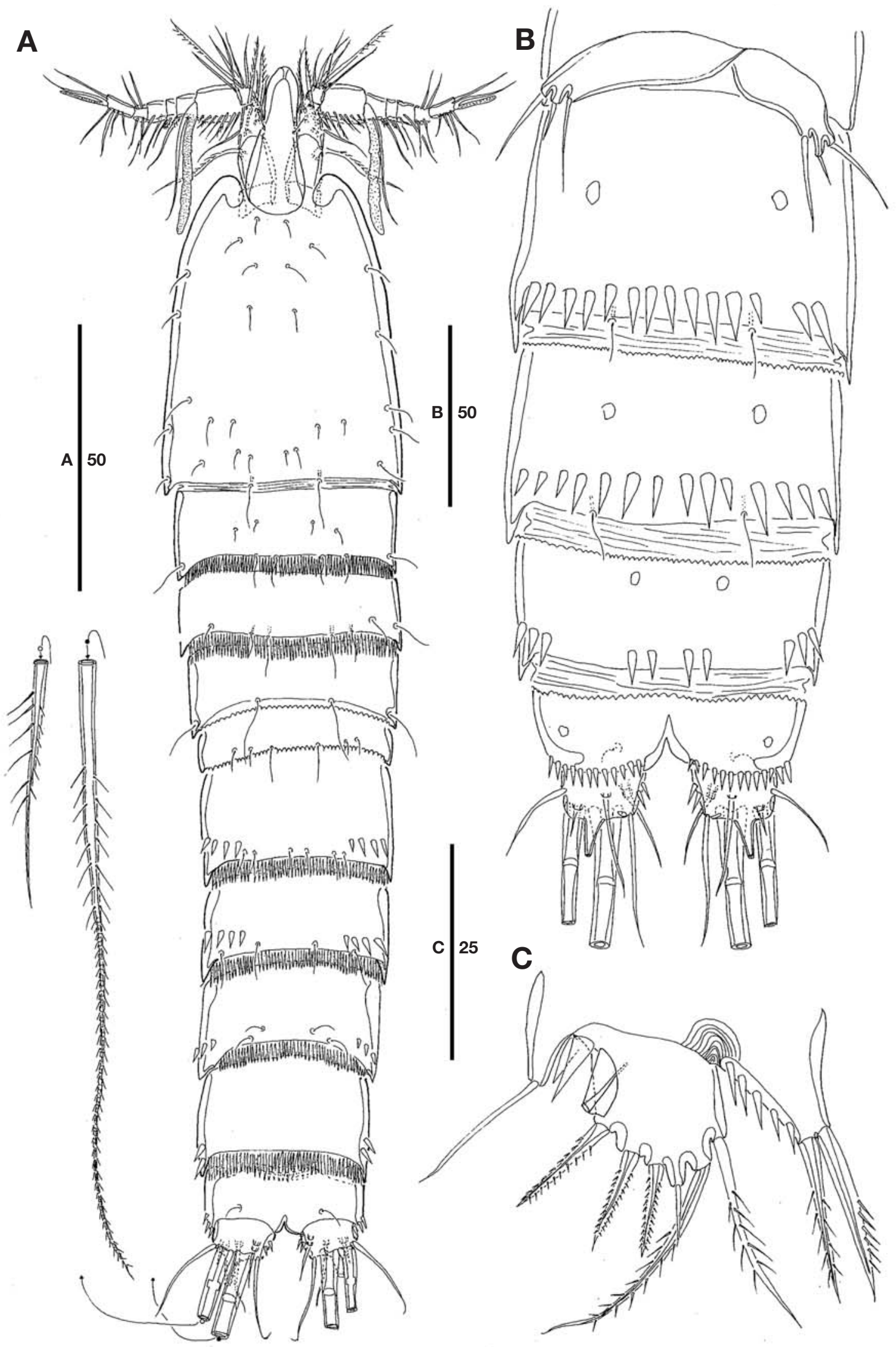

Fig. 6. Sinamphiascus dominatus, male. A. habitus, dorsal. B. urosome, ventral. C. P5. 


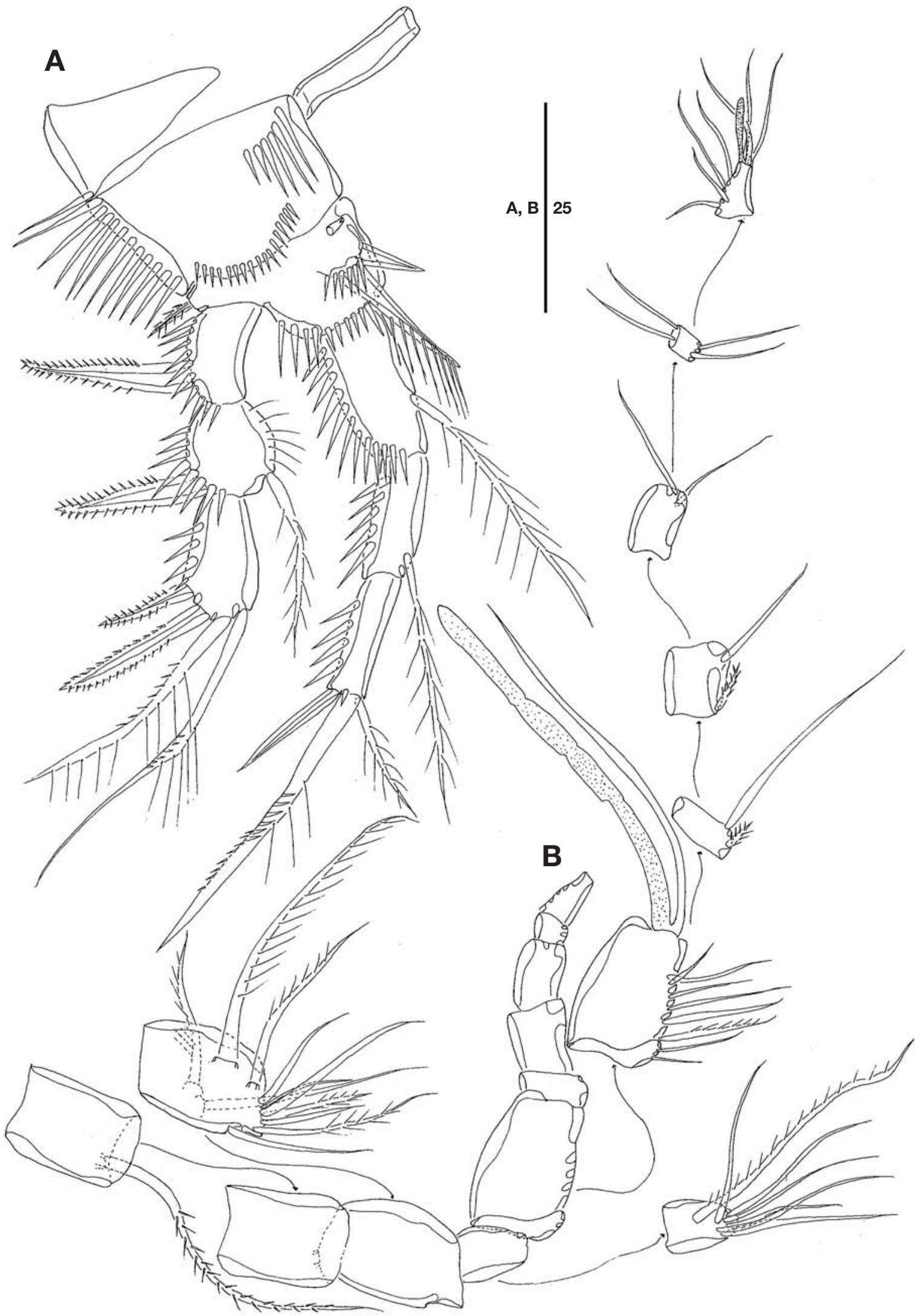

Fig. 7. Sinamphiascus dominatus, male. A. P1. B. antennule. 


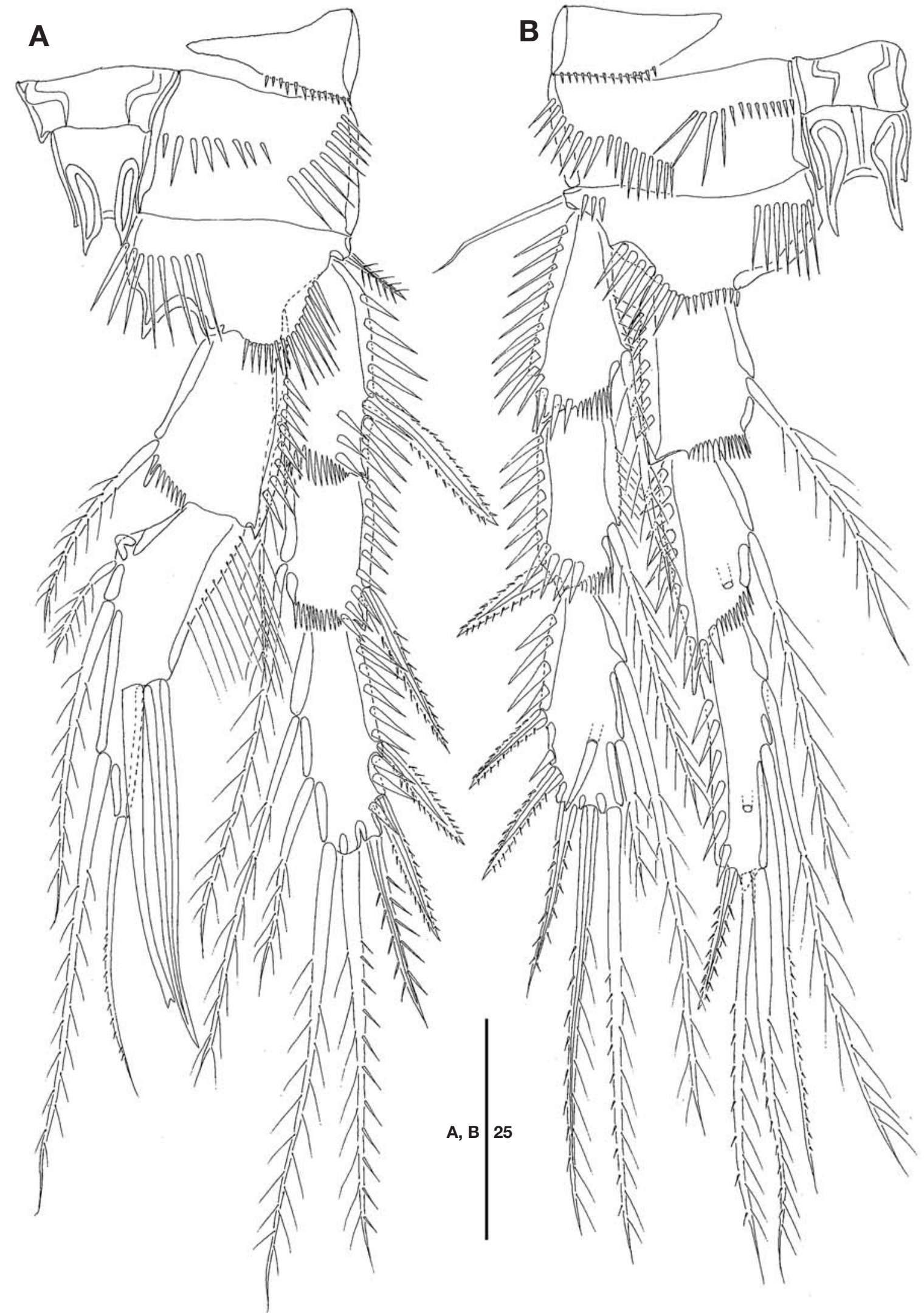

A

Fig. 8. Sinamphiascus dominatus, male. A. P2. B. P3. 
veloped, sclerite of P2 with paired row of spinules. Basis with rows of spinules on inner and distal margin; outer basal seta bipinnate (P2), smooth (P3) and unipinnate (P4) in order. Endopod slightly longer than exopod in P2 and P3 and slightly shorter than exopod in P4; distal segment longest; all segments with row of strong spinules on outer margin and segments 1 and 2 of each rami with hyaline frills on inner distal margin.

Armature formula for P1-P4 as follows:

$\begin{array}{lll} & \text { Exopod } & \text { Endopod } \\ \text { P1 } & 0: 1: 022 & 1: 1: 021 \\ \text { P2 } & 1: 1: 223 & 1: 2: 121[1: 312 \text { in ठ] } \\ \text { P3 } & 1: 1: 223 & 1: 1: 221 \\ \text { P4 } & 1: 1: 323 & 1: 1: 121\end{array}$

P5 (Fig. 2F). Baseoendopod not fused medially; baseoendopod and exopod separate; Inner expansion of baseoendopod reaching about half length of exopod and with small hyaline area near base of exopod; 1 small pore on anterior surface; armed with 5 pinnate spines. Exopod about twice as long as broad, with few spinules on inner and outer margin and 1 small pore on anterior surface; with 6 elements ( 1 bipinnate inner spine, 2 plumose distal setae, and 3 pinnate outer spines).

Male: Body 270-360 $\mu \mathrm{m}$ long, similar to female (Fig. 6A). Sexual dimorphism in urosome, A1, P1 basis, P2 endopod, P3 exp-3 and P5.

Urosome (Fig. 6B) urosomite-2 and-3 not fused. Genital somite with vestigial P6 forming asymmetrical plate, each one bearing 3 setae.

Antennule (Fig. 7B) 10-segmented, and haplocer with geniculation between segments 7 and 8 . Aesthetascs on segments 5 and 10. Armature formula as follows: 1-[1 bipinnate], 2-[6 bare +5 plumose], 3-[6 bare +1 plumose], 4-[0], 5-[7 bare +1 plumose $+(1+\mathrm{ae})], 6-[1$ bare +1 pinnate spine], 7-[1 bare +1 pinnate spine], 8 -[2 bare], 9-[4 bare], 10-[4 bare+acrothek], apical acrothek consisting of aesthetasc fused basally to 2 slender, naked setae.

P1 (Fig. 7A) basis with 2 chitinous projections near inner margin; second inner projection unipectinate. Exp3 with 2 plumose setae and 2 bipinnate setae.

P2 (Fig. 8A) protopod and exopod as in female. Endopod modified to 2-segmented; enp-1 as in female except inner seta slightly shorter, enp-2 with 1 small projection on inner margin and 3 plumose setae on inner margin, 1 unipinnate seta on distal margin, 1 large spine with 1 concave tip and 1 spine on outer margin.

P3 (Fig. 8B) as in female, except hyaline tube-pore present on anterior face of exp-3.

P5 (Fig. 6C) fused medially; baseoendopod with 2 pinnate setae; exopod about as long as broad, with 6 setae and spines; 1 large pore on pronounced peduncle on proximal outer margin along with 1 row of spinules.

Distribution. China (Bohai Sea), Korea (off Jeju Island and Southern West Sea).

Ecology. This species inhabits sandy and muddy sand bottoms in sublittoral zone 40-130 m in depth.

Remarks. The Korean Specimen displays distinct character in P1 exp-3 arming only two outer spines instead of three in the original description (Mu and Gee, 2000). Except for this character, present specimen clearly belongs to $S$. dominates $\mathrm{Mu}$ and $\mathrm{Gee}, 2000$. Mu and Gee (2000) described that P1 exp-3 with three elements on outer margin, of which, proximal element is a small seta and distal elements are spines, however it is not clear whether the proximal element is a seta in their figure (See figure 19A in $\mathrm{Mu}$ and Gee, 2000). There is no definite difference between the proximal element and large spinules on the outer margin of P1 exp-3 in both the original description and the present Korean specimens. We tentatively conclude that the proximal element is not a small seta as $\mathrm{Mu}$ and Gee (2000) claimed but an additional spinule. Consequently the four elements on the P1 exp-3 are able to support more strongly the close relationship between Sinamphiascus and Haloschizopera as mentioned in $\mathrm{Mu}$ and Gee (2000). The present specimens have further differences with original description as follows: female-1) segment 2 and 3 on antennule with 12 and 4 elements compared with 11 and 7 elements in Mu and Gee (2000): 2) labrum with 4 teeth compared with 5 teeth: 3 ) mandiblular coxa with 1 tricuspid and 2 bicuspid teeth compared with 3 bicuspid: 4) leg 6 with 2 long setae and 1 short seta compared with 1 long seta and 2 small setae: 5) seta I on caudal ramus located on a small peduncle compared with none: male-6) segment 4 without seta and segment 5 with 10 element compared with 2 and 9 elements in male: 7) exopod of leg 5 quadrate compared with longer than wide in male. The above characters between the original description and the present study are regarded to minor discrepancies within the ranges of observational errors, or individual variations.

\section{ACKNOWLedgements}

This research was financially supported by the project of the Discovery of Korean Indigenous Species Project, NIBR (National Institute of Biological Resources). The authors extend their appreciation to Mrs. Hee Jin Moon (Hanyang University) for her great help in preparing the artwork.

\section{REFERENCES}

Boxshall, G.A. and S.H. Halsey. 2004. An introduction to copepod diversity. Part I. The Ray Society, London. 421 pp. 
Burgess, R. 2001. Am improved protocol fro separating meiofauna from sediments using colloidal silica sols. Mar. Ecol. Prog. Ser. 214:161-165.

Chang, C.Y. 2009. Three miraciid copepods (Harpacticoida, Miraciidae) from South Korea. Korean J. Syst. Zool. 25 (3):215-225.

Huys, R., J.M. Gee, C.G. Moore and R. Hamond. 1996. Marine and brackish water harpacticoid copepods Part 1. Synopses of the British Fauna (New Series) 51:1-352.

Kim, K.C., E.-O. Park and E. Lee. 2011. First record of Onychostenhelia bispinosa (Copepoda: Harpacticoida: Miraciidae) from Korea. Bulletin of NIBR 2(2):55-65.

Lee, W., H.Y. Soh and H.-L. Suh. 2007. A new species of the genus Amphiascoides (Copepoda: Harpacticoida) from Korean Waters. Proc. Biol. Soc. Wash. 120(3):279-292.

Mu, F. and J.M. Gee. 2000. Two new species of Bulbamphiascus (Copepoda: Harpacticoida: Diosaccidae) and a related new genus, from the Bohai Sea, China. Cah. Bio. Mar 41:103-135.

Park, E.-O. and W. Lee. 2011. New record of Scottolana bul- bifera (Copepoda: Harpacticoida: Canuellidae) from Korean. Bulletin of NIBR 2(2):66-75.

Song, S.J. and C.Y. Chang. 1995. Marine harpacticoid copepods of Chindo Island, Korea. The Korean J. Syst. Zool. 11:65-77.

Song, S.J., H.S. Rho and W. Kim. 2007. A new species of Amonardia (Copepoda: Harpacticoida: Miraciidae) from the Cultivated Brown Alga, Undaria pinnatifida. Integr. Biosci. 11:69-77.

Song, S.J., S.G. Yun and C.Y. Chang. 1999. New records on three harpacticoid copepods associated with marine macroalgae in Korea. J. Fish. Sci. Technol. 2:189-198.

Wells, J.B.J. 2007. An annotated checklist and keys to the species of Copepoda Harpacticoida (Crustacea). Zootaxa 1568:1-872.

Yoo, K.-I. and W.-C. Lee. 1995. Marine harpacticoid copepods from the Korean waters. J. Yellow Sea 1:34-49.

Submitted: January 17, 2012, Accepted: February 9, 2012 